\title{
Distress prior to undergoing hematopoietic stem cell transplantation: demographic and symptom correlations and establishing a baseline
}

This article was published in the following Dove Press journal:

Patient Related Outcome Measures

15 September 2016

Number of times this article has been viewed

\author{
Sean Robinson Smith' \\ Mary Elizabeth Hobson ${ }^{2}$ \\ Andrew J Haig' \\ 'Department of Physical Medicine \& \\ Rehabilitation, ${ }^{2}$ Adult Blood and \\ Marrow Transplantation Program, \\ Division of Hematology/Oncology, \\ University of Michigan, Ann Arbor, \\ MI, USA
}

Background: Distress can arise from physical and/or psychosocial impairments and has been documented in patients after hematopoietic stem cell transplantation in the outpatient setting. It has not been evaluated in inpatients admitted to undergo the transplant, nor has potential correlations with length of hospital stay, physical function, and pain after receiving the transplant. Objectives: To measure distress in patients admitted to the hospital to undergo hematopoietic stem cell transplantation, and to evaluate potential correlations with length of hospital stay, physical function, pain, and depression/anxiety.

Methods: Eighty patients were given a questionnaire to report levels of distress and physical and psychosocial functioning. Hierarchical multiple regression analysis was used to test the relationship of demographic and transplant factors with length of stay (LOS), distress, presence of pain, and depression/anxiety.

Results: Patients reported pretransplant distress with an average score of 2.2 out of 10 , and 16 out of 80 patients reported clinically relevant distress. Pain was reported by $42.5 \%$ of patients, and $28.8 \%$ reported depression/anxiety. Physical functioning was generally high. Distress was correlated with depression/anxiety $(P$-value $<0.01)$ and pain $(0.04)$ but not with LOS, physical function, patient age, or transplant type.

Conclusion: LOS after receiving stem cell transplant was not related to pretransplant distress. Distress exists pretransplant but is generally low. Pain and the presence of depression/anxiety may be risk factors for distress. Measuring distress prior to transplant gives a baseline from which to measure changes, potentially leading to earlier intervention.

Keywords: Distress Thermometer, bone marrow transplant, cancer rehabilitation, BMT rehabilitation, symptom management, patient-reported outcomes

\section{Introduction}

Hematopoietic stem cell transplantation (HSCT) with the intent to cure hematologic malignancies is performed over 50,000 times a year, ${ }^{1}$ and carries with it potential deleterious side effects ${ }^{2-5}$ that can cause significant morbidity and mortality. Often, patients undergoing HSCT - either an autologous transplant using the patient's own stem cells or an allogeneic transplant using donor cells - have completed treatment consisting of chemotherapy and potentially radiation therapy and/or surgery. These oncologic treatments can lead to physical, cognitive, and/or psychosocial distress, though level of, and factors contributing to, distress in patients admitted to the hospital to undergo HSCT is unclear.

Distress, as defined by the National Comprehensive Cancer Network (NCCN) as "an unpleasant emotional experience that can be psychological, social, and/or
Correspondence: Sean Robinson Smith Department of Physical Medicine \& Rehabilitation, University of Michigan, 325 East Eisenhower Parkway, Suite 100, Ann Arbor, MI 48I08, USA

Tel +l 7349367210

Fax+l 7346156713

Email srsz@med.umich.edu 
spiritual", can be debilitating and underdiagnosed, ${ }^{6}$ and has been referred to as the "sixth vital sign" given its value in providing a comprehensive look at how physical, emotional, and other factors may affect a patient. ${ }^{7}$ The Commission on Cancer, the commission within the American College of Surgeons which accredits national cancer centers, requires distress screening for all patients, although it does not recommend a specific screening tool. ${ }^{8}$ Additionally, the Institute of Medicine identifies management of patient distress as a key component of delivering high-quality cancer care. ${ }^{9}$ Clinically relevant distress is defined as an overall patient-reported numeric value of $\geq 5$ on a scale of $1-10$, and suggests that intervention for the distressing symptom(s) be made, such as a referral to a physical medicine and rehabilitation physician, a psychiatrist, or others. ${ }^{7,10}$ While evaluating distress does not replace a more comprehensive psychological and physical examination, identifying the presence of distress can identify when attention to factors negatively impacting patients is warranted.

Psychosocial distress has been shown to range from $13 \%$ to $51 \%$ in the HSCT population, ${ }^{11,12}$ and higher levels of distress are associated with lower quality of life. ${ }^{12}$ Trask et al prospectively looked at distress during an outpatient evaluation by a hematologist of potential HSCT patients, finding that this patient population has distress; however, this study did not evaluate patients selected for HSCT and admitted to undergo the transplant. ${ }^{11}$ Their patients included those with advanced disease, or poor physical, cognitive, and/ or psychosocial function, who ultimately would not undergo HSCT and therefore may have had higher levels of distress than the patients selected to undergo the treatment.

Components of distress prior to HSCT - including somatic dysfunction, depression, and anxiety - are correlated with poorer survival outcomes, although it is unclear if these factors are predictors of survival. ${ }^{12,13}$ Additionally, depression and distress have been shown to reduce treatment compliance in patients undergoing HSCT, with possible implications on survival outcomes for post-HSCT patients with comorbidities requiring long-term management such as chronic graft-versus-host disease (GVHD). ${ }^{14}$ Another study found that pretransplant patient-reported physical impairment predicts worse physical function at 1 year posttransplant, that depression and anxiety posttransplant were associated with family conflicts and less severe GVHD, and that physical function was predicted by the severity of GVHD. ${ }^{15}$ It did not correlate physical function with depression and anxiety in the way that distress, which is more inclusive of the overall symptom cluster experienced by patients, does. Another study looked at pre-HSCT depression, and found that there is a difference in depression levels pre- and post-HSCT but that it was not always predictable. ${ }^{16}$ This argues that having a baseline was valuable in identifying worsening depression in patients, especially given that pre-HSCT depression was often not severe. ${ }^{16}$

Given that distress, and the physical and psychosocial components of distress, has implications on long-term outcomes of HSCT, monitoring this population and establishing a baseline - to identify changes and lead to earlier intervention - may be beneficial. Prescreening for symptoms is emerging as a valuable tool for monitoring patient symptoms in $\mathrm{HSCT}^{17}$ and other diagnoses, including breast cancer ${ }^{18}$ and chemotherapy-induced peripheral neuropathy. ${ }^{19}$ No study has evaluated distress at the time of admission to the hospital for HSCT, which provides the optimal baseline from which to measure future distress levels, and to the authors' knowledge, no study has measured correlation of distress with physical and psychosocial factors. In this largely descriptive study, we evaluated distress in patients about to undergo HSCT, and explored the relationship of this distress with different factors, including physical function, presence of depression and/or anxiety, presence of pain, age, and type of HSCT.

\section{Methods \\ Study design}

Eighty patients admitted to the University of Michigan Adult Bone Marrow Transplantation Unit from October 2012 to March 2014 to undergo first-time allogeneic or autologous HSCT were given a questionnaire to evaluate distress and physical functioning. Distress was evaluated using the NCCN's Distress Thermometer (DT), ${ }^{20}$ which asks the patient to rate their overall distress from 1 to 10 and which further asks about specific stressors that are affecting the patient (Table S1). The DT has been shown in the HSCT patient population to be strongly correlated with existing measures in assessing patient symptoms, ${ }^{21}$ and to be able to identify physical and psychosocial impairments. ${ }^{22}$

Physical function was evaluated by five questions from the Barthel Index, ${ }^{23}$ a measure of physical independence, with these questions specifically asking about a person's ability to independently dress, ambulate 50 feet, climb stairs, bathe, and groom. Although originally constructed as a clinician-recorded outcome measure, using the Barthel Index for patients to describe their own level of functioning has been shown to correlate well with other validated tools assessing function, albeit not in the chronic GVHD 


\begin{tabular}{|c|c|}
\hline $\begin{array}{l}\text { Abbreviated version of the Barthel Index, as } \\
\text { answered by patients (check box for which } \\
\text { answer is appropriate) } \\
\text { Self-care } \\
\text { - I have no problems dressing myself } \\
\text { - I have some problems dressing myself } \\
\text { - I am unable to wash or dress myself } \\
\text { Ambulating } 50 \text { feet } \\
\text { - I can walk } 50 \text { feet by myself } \\
\text { - I need someone to support me to walk } 50 \text { feet } \\
\text { - I can use a wheelchair to move } 50 \text { feet } \\
\text { - I cannot move } 50 \text { feet } \\
\text { Climbing stairs } \\
\text { - I can walk independently without a handrail } \\
\text { - I need a handrail or a person to help me } \\
\text { climb stairs } \\
\text { Bathing I cannot climb stairs } \\
\text { - I can bathe independently or take a shower } \\
\text { independently } \\
\text { - I cannot shower and need help to bathe } \\
\text { Grooming } \\
\text { - I can brush my hair and teeth independently } \\
\text { - I need help brushing my hair or my teeth }\end{array}$ & $\begin{array}{l}\text { Pain and depression/anxiety screen } \\
\text { Pain } \\
\text { - I am in some pain or I am in severe pain } \\
\text { - I am not in pain } \\
\text { Depression/anxiety } \\
- \text { I sometimes or I always feel depressed or anxious } \\
\text { - I do not feel depressed or anxious }\end{array}$ \\
\hline
\end{tabular}

Figure I Barthel Index items, and depression/pain questions.

population. $^{24,25}$ Furthermore, Ploughman et al found that the patient-reported Barthel Index compared favorably with other patient-reported functional measures, correlated with clinician-assessed outcome measures, and was relatively easy for patients to understand. ${ }^{26}$ In these studies, the Index was used to evaluate non-stroke disabled populations. The entirety of the Barthel Index, which was designed for neurologic disorders and emphasizes functional independence, was not used due to the lack of relevance for all of the questions to the HSCT population; for example, the entire 10-point Barthel Index asks about neurogenic bowel and bladder, and these symptoms are not typically found in the HSCT population. The Barthel Index has been modified previously to better address needs within specific patient populations; this is the foundation for the Modified Barthel Index, ${ }^{27}$ sometimes used in evaluating stroke patients, and it has been suggested that the tool may perform better when modified to evaluate problems specific to certain populations, and eliminating irrelevant items may improve validity. ${ }^{26}$ Doing so would potentially make it easier for patients to accurately record their scores, without biasing the results. Point values were assigned to these items of this abbreviated Barthel Index, and a total score was calculated for each patient, with a higher score indicating a higher level of functional independence. Finally, patients were also asked about how frequently they experience pain and depression/ anxiety (never, sometimes, always). Patients were told to ask questions to clarify any confusing questions, and there was no apparent difficulty in patients reporting depression/ anxiety and pain. The Barthel Index items, overall distress level, and pain and depression questions are presented in Figure 1.

The questions were combined into a single questionnaire given to patients upon admission to the Bone Marrow Transplantation Unit prior to initiating the transplant process. A printout of the questionnaire was provided to the patients upon arrival to the unit by a nurse, and later collected by a physiatrist. Age, sex, and hematologic malignancy were recorded for each patient. Later, chart review discerned length of stay (LOS) while admitted for the transplant. Data were then electronically recorded and entered into a password-protected secure Excel spreadsheet, and analysis was performed using SPSS (version 22) software (IBM Corporation, Armonk, NY, USA).

Patients aged 18 years or older admitted to undergo an allogeneic or autologous HSCT for the first time were included in the study. Patients too sick or cognitively impaired to fill out the form were excluded. The University of Michigan Institutional Review Board (No HUM00075059) approved the study prior to implementation. 


\section{Sample characteristics}

Twenty-nine patients undergoing allogeneic and 51 undergoing autologous HSCT completed the questionnaire (Table 1). The average age was 56.6 years for the allogeneic group, 58.2 years for the autologous group, and 57.6 years when both transplant types were combined. The allogeneic group had 12 male and 17 female participants, and the autologous group had 35 male and 16 female participants, making a combined sample of 47 male and 33 female participants in the study. The preHSCT diagnoses for allogeneic patients were acute myeloid leukemia (AML; 15 patients), non-Hodgkin lymphoma (five), acute lymphoblastic leukemia (four), Hodgkin lymphoma (two), myelodysplastic syndrome (one), chronic myelogenous leukemia (one), and Waldenstrom macroglobulinemia (one). Pre-HSCT diagnoses for autologous patients were multiple myeloma (36 patients), non-Hodgkin lymphoma (eleven), Hodgkin lymphoma (two), AML (one), and yolk sac tumor (one). The difference in diagnoses in each cohort is due to the indication for each type of transplant, and was expected. For example, patients with multiple myeloma undergo autologous and not allogeneic transplants. Written consent was obtained from all patients.

\section{Statistical analysis}

In the analysis, pain and a combined depression/anxiety rating were treated as binary (having the symptom or not) because responses were skewed to the left (very few patients indicated extreme pain or anxiety/depression), with few patients indicating extreme values of these variables. Distress was averaged, and the frequency of values $>4$ were calculated. Hierarchical multiple regression analysis was used to test the relationship of demographic and transplant type with outcomes of LOS and distress (transplant type was included due to differences in pretransplant diseases for the autologous and allogeneic transplants). Preliminary analyses were conducted to ensure no violation of the assumptions of normality, linearity, multicollinearity, and homoscedasticity. For LOS, pain, age, transplant type, and the abbreviated Barthel Index score were entered in the first step, and distress was entered in the second step. For distress, the same first step was entered, and depression/ anxiety was entered in the second step. Depression/anxiety was not used in the model for LOS due to a strong independent relationship with distress. Results were determined to be significant by having a $P$-value $<0.05$.

\section{Results}

Sixteen patients (eight allogeneic, eight autologous) indicated clinically relevant distress with a score of $\geq 5$. The range was from 0 to 9 , and no statistically significant difference was observed between the two transplantation types, suggesting that pretransplant diagnosis may not have an effect on pretransplant distress. More physical symptoms were indicated on the DT than the practical, family, emotional, and spiritual symptom domains combined (Table 2). Distress with regard to sleep was the most prevalent, with 31 out of 80 patients indicating a problem, followed by nausea (27), tingling (27), fatigue (24), and pain (24). Nervousness (23) was the most prevalent nonphysical symptom, followed by worry (21), insurance issues (17), and fears (15). Most patients had a high level of physical independence, and scores on the abbreviated Barthel Index ranged from 25 to 45 (perfect score), with an average of 42.13 , and 43 out of 80 having a perfect score. Only seven patients scored $<40$.

Distress had a statistically significant independent relationship with depression/anxiety $(P<0.001)$. When the impact of the independent variables Barthel score, presence of pain, presence of depression/anxiety, and type of transplant on distress was calculated, the $R$-square value was 0.257 (Table 3 ). Removing depression/anxiety from the regression analysis due to the two variables having a strong correlation, the $R$-square value dropped to $0.069(6.9 \%)$, indicating that only $6.9 \%$ of distress was predicted by presence of pain, and physical function, age, and transplant type. Pain location was reported by patients on a drawing of a human body, and was not described by patients in either HSCT cohort as consistently being in the same location. Pain in shoulders, lower and upper back, neck, and lower extremity was described, and occasionally, patients reported more than one area of pain, again, without a distinct trend.

Table I Patient demographics

\begin{tabular}{|c|c|c|}
\hline Value & $\begin{array}{l}\text { Autologous } \\
(n=5 I)\end{array}$ & $\begin{array}{l}\text { Allogeneic } \\
(n=29)\end{array}$ \\
\hline Mean age (range, SD) (years) & $58.2(30-71,9.9)$ & $56.6(29-69,10.0)$ \\
\hline Sex & $\begin{array}{l}16 \text { females, } \\
35 \text { males }\end{array}$ & $\begin{array}{l}17 \text { females, } \\
12 \text { males }\end{array}$ \\
\hline \multicolumn{3}{|l|}{ Diagnosis } \\
\hline Non-Hodgkin lymphoma & 11 & 5 \\
\hline Multiple myeloma & 36 & 0 \\
\hline Hodgkin lymphoma & 2 & 2 \\
\hline Acute lymphoblastic leukemia & 0 & 4 \\
\hline Acute myeloid leukemia & I & 15 \\
\hline $\begin{array}{l}\text { Chronic myelogenous } \\
\text { leukemia }\end{array}$ & 0 & 1 \\
\hline Myelodysplastic syndrome & 0 & I \\
\hline Yolk sac tumor & I & 0 \\
\hline $\begin{array}{l}\text { Waldenstrom } \\
\text { macroglobulinemia }\end{array}$ & 0 & I \\
\hline $\begin{array}{l}\text { LOS after transplant (average } \\
\text { in days) }\end{array}$ & 17.4 & 22.7 \\
\hline
\end{tabular}

Abbreviations: SD, standard deviation; LOS, length of stay. 
The impact of these variables on LOS was also calculated. Although LOS was found to have a bivariate significant correlation with Barthel score, presence of pain, and distress, this significance was lost after analysis was performed controlling for age and type of transplant. $R$-square value assessing the impact on LOS by these variables was 0.286 . When distress was removed from the analysis, the $R$-square value dropped only to 0.271 , showing that pretransplant distress has little impact on hospital LOS. Presence of depression/anxiety was not included in LOS analysis due to its strong correlation with distress. LOS was only correlated with the type of transplant received after all other factors were accounted for $(P<0.001)$. Allogeneic transplant recipients had a longer LOS, which is consistent with known medical practice and is not novel information.

\section{Discussion}

Distress was present in patients admitted to undergo first-time HSCT; however, the majority of patients did not experience clinically relevant distress, that is, a value $>4$. Patients more frequently selected physical symptoms as causing distress compared to psychosocial stressors; however, the prescence of depression and/or anxiety was strongly correlated with distress. The physical symptoms with which patients indicated most frequently that they have distress had to do with pain, fatigue, and similar symptoms. Physical symptoms felt by patients upon admission for a HSCT had less to do with physical function, that is, ability to carry out a task, than with what a patient is physically feeling, such as pain, as evidenced by patient-reported high functioning on the Barthel Index. The degree of distress upon admission for HSCT did not impact LOS, nor did the presence of pain, a person's age, or his/her physical function.

This is the first paper to evaluate distress in patients prior to undergoing HSCT, which is important for several reasons. For one, there is a growing emphasis on early detection of symptoms to potentially make treatment more effective and efficient. Second, having a baseline symptom assessment informs clinicians when there has been a change in the patient's status. For example, if a patient's distress level increases from a 2 out of 10 prior to HSCT to a 4 out of 10 at day 100 post-HSCT, a clinician should evaluate why a patient's distress level doubled, even if the overall distress level may not be considered high. Finally, distress itself is becoming a more widely recognized aspect of cancer symptom management screening, as it encompasses myriad symptoms across the psychosocial and physical spectrum, creating a comprehensive picture of what a patient is experiencing.
Table 2 Survey results $(n=80)$

\begin{tabular}{|c|c|}
\hline \multirow{2}{*}{\multicolumn{2}{|c|}{ Distress Thermometer, average }} \\
\hline & \\
\hline Average score of those with nonzero distress & 3.4 \\
\hline Number of patients with distress values $>4$ & 16 \\
\hline Number of patients with zero distress & 28 \\
\hline Abbreviated Barthel Index score, average & 42.1 \\
\hline Respondents with some pain & $34(42.5 \%)$ \\
\hline Respondents with some depression/anxiety & $23(28.8 \%)$ \\
\hline \multicolumn{2}{|c|}{ Frequency of physical symptoms on Distress Thermometer } \\
\hline Sleep & 31 \\
\hline Nausea & 27 \\
\hline Tingling & 27 \\
\hline Fatigue & 24 \\
\hline Pain & 24 \\
\hline Dry skin & 20 \\
\hline Constipation & 16 \\
\hline Nasal congestion & 15 \\
\hline Memory & 12 \\
\hline Eating & 10 \\
\hline Appearance & 7 \\
\hline Diarrhea & 7 \\
\hline Urination & 6 \\
\hline Feeling swollen & 6 \\
\hline Getting around & 5 \\
\hline Indigestion & 4 \\
\hline Sexual & 4 \\
\hline Bathing & 2 \\
\hline Breathing & 2 \\
\hline Mouth sores & 2 \\
\hline Fevers & I \\
\hline \multicolumn{2}{|c|}{ Frequency of nonphysical symptoms on Distress Thermometer } \\
\hline Nervousness & 21 \\
\hline Worry & 21 \\
\hline Insurance & 17 \\
\hline Fears & 15 \\
\hline Sadness & 10 \\
\hline Work/school & 7 \\
\hline Housing & 5 \\
\hline Transportation & 5 \\
\hline Loss of interest & 4 \\
\hline Close friend & 2 \\
\hline Child care & 1 \\
\hline Children & I \\
\hline Partner & 1 \\
\hline Spiritual & 1 \\
\hline \multicolumn{2}{|l|}{ Pain } \\
\hline I have no pain or discomfort & 46 \\
\hline I have some pain or discomfort & 31 \\
\hline I have extreme pain or discomfort & 3 \\
\hline \multicolumn{2}{|l|}{ Anxiety/depression } \\
\hline I am not anxious or depressed & 57 \\
\hline I am moderately anxious or depressed & 20 \\
\hline I am extremely anxious or depressed & 3 \\
\hline
\end{tabular}

This study has several weaknesses. The evaluation of physical functioning is limited, and nearly all patients were either completely independent or nearly independent in the physical functioning domains assessed by the questions taken from the Barthel Index. While it makes the potentially inter- 
Table 3 Analyzing distress level and length of stay

\begin{tabular}{|c|c|c|c|c|c|}
\hline \multicolumn{6}{|c|}{ Distress: relationship with age, transplant type, presence of pain, presence of depression/anxiety, and Barthel score } \\
\hline Analysis & Age & Transplant type & Pain & Depression/anxiety & Barthel \\
\hline Bivarate & 0.288 & 0.204 & $0.043 *$ & $<0.001 *$ & 0.073 \\
\hline Pearson & 0.064 & 0.094 & 0.194 & 0.404 & -0.164 \\
\hline$R$-square & & & 0.257 & & \\
\hline Adjusted $R$-square & & & 0.207 & & \\
\hline$R$-square removing depression/anxiety & & & 0.069 & & \\
\hline \multicolumn{6}{|c|}{ LOS: relationship with age, transplant type, presence of pain, distress level, and Barthel score } \\
\hline Analysis & Age & Transplant type & Pain & Distress & Barthel \\
\hline Bivariate & 0.259 & $<0.001 *$ & 0.064 & 0.219 & 0.489 \\
\hline Pearson & -0.073 & 0.510 & -0.171 & -0.088 & -0.003 \\
\hline$R$-square & & & 0.286 & & \\
\hline Adjusted $R$-square & & & 0.238 & & \\
\hline$R$-square removing distress from the model & & & $0.27 \mathrm{I}$ & & \\
\hline
\end{tabular}

Note: $*$ Statistical significance with a $P$-value $<0.05$.

Abbreviation: LOS, length of stay.

esting point that patients generally have high physical function prior to HSCT - which may not have been assumed given the chemotherapy and other treatments administered prior to transplant - it did not provide an assessment with much variability, thus not comprehensively allowing evaluation of distress vis-à-vis physical symptoms. Nevertheless, very few patients indicated distress related to "getting around" on the DT, suggesting that these Barthel Index questions painted an accurate picture of physical function in this population (Table S1). Given that only more physically robust patients undergo HSCT, the transplant process may select away from patients with physical compromise, and therefore, we cannot tell if poor function leads to distress. Future studies should look at pain and other physical symptoms more closely as they relate to distress prior to transplantation.

Next, the evaluation of pain and depression and/or anxiety was limited to a yes/no format, and did not quantify the degree of these symptoms other than a patient indicating if they had "some" or "extreme" pain or depression/anxiety. The fact that very few indicated extreme levels of those symptoms makes this less problematic; however, future studies should look more closely at patients with moderate symptoms, and how those interact with distress levels.

Finally, the sample data were skewed to have more autologous transplant recipients than allogeneic. There are different pre-HSCT disease processes for each transplant type, and it is unclear if there are significant differences between the two. For example, both AML and multiple myeloma patients are at a high risk of developing chemotherapy-induced peripheral neuropathy, but differences between these groups have not been evaluated. Nevertheless, all patients about to undergo a HSCT need to reach a certain threshold of physical and emotional capacity to tolerate a HSCT, so very low-functioning patients, such as those with severe pain and/or weakness, may be selected out of studies like this by virtue of not being able to undergo HSCT. Transplant type was, however, controlled for in our analysis, and it did not have an impact on distress. Severity and duration of pretransplant disease would be useful and should be looked at in the future. Future studies should also seek to enroll similar numbers of patients for each transplant, or focus only on one type of transplant since studying patients undergoing either alloHSCT or autoHSCT may allow for more in-depth analysis of the subgroups. Future studies should also consider enrolling a greater number of patients; a total of 80 subjects provides a sufficiently broad picture of patients undergoing HSCT, but larger numbers may help tease out subtle findings. Given the relatively high function and low overall distress in patients in this study, however, it is unclear if a larger study would find meaningful differences.

This study is important because it is distinct from previous studies evaluating distress during the outpatient phase prior to potential HSCT. Patients admitted to the hospital for the transplant understand that the transplant may help them - thus positively affecting distress level - but also may have increased distress related to several factors, including but not limited to concerns about the transplant itself, being in a hospital and not outpatient setting, and having had a presumably longer course of pre-HSCT treatment for their hematologic malignancy than those not yet cleared for HSCT (potentially leading to increased pain, fatigue, cognitive deficits, and more). Measuring distress at the time of admission prior to HSCT thus would create the optimal baseline from which to assess changes in distress level. 


\section{Conclusion}

Distress is present in patients about to undergo a HSCT, albeit often not at clinically relevant levels, and was correlated with the presence of pain and of depression/anxiety. Nevertheless, obtaining a baseline assessment of distress can help clinicians more easily identify changes, potentially leading to earlier intervention. Patients about to undergo HSCT had high physical functioning in terms of mobility and self-care but did report many physical symptoms, such as pain and fatigue, which contributed to distress. Future studies should focus on the change in distress over time, and contributing factors.

\section{Acknowledgment}

The authors wish to acknowledge Claire Kalpakjian, $\mathrm{PhD}$, for providing statistical assistance in this study.

\section{Disclosure}

The authors report no conflicts of interest in this work.

\section{References}

1. World Health Organization. Haematopoietic Stem Cell Transplantation HSCtx. Geneva: World Health Organization; 2015.

2. Bellm LA, Epstein JB, Rose-ped A, Martin P, Fuchs HJ. Patient reports of complications of bone marrow transplantation. Support Care Cancer. 2000;8(1):33-39.

3. Bowden RA, Meyers JD. Infection complicating bone marrow transplantation. In: Rubin RH, Young LS, editors. Clinical Approach to Infection in the Compromised Host. New York: Springer; 1994:601-628.

4. Smith SR, Haig AJ, Couriel DR. Musculoskeletal, neurologic, and cardiopulmonary aspects of physical rehabilitation in patients with chronic graft-versus-host disease. Biol Blood Marrow Transplant. 2015;21(5):799-808.

5. Soubani AO, Miller KB, Hassoun PM. Pulmonary complications of bone marrow transplantation. Chest. 1996;109(4):1066-1077.

6. Fashoyin-aje LA, Martinez KA, Dy SM. New patient-centered care standards from the commission on cancer: opportunities and challenges. J Support Oncol. 2012;10(3):107-111.

7. Howell D, Olsen K. Distress-the 6th vital sign. Curr Oncol. 2011;18(5): 208-210.

8. Holland JC, Andersen B, Breitbart WS, et al. Distress management. $J$ Natl Compr Canc Netw. 2010;8(4):448-485.

9. Seow H, Snyder CF, Shugarman LR, et al. Developing quality indicators for cancer end-of-life care: proceedings from a national symposium. Cancer. 2009;115(17):3820-3829.

10. Hoffman BM, Zevon MA, D'arrigo MC, Cecchini TB. Screening for distress in cancer patients: the NCCN rapid-screening measure. Psychooncology. 2004;13(11):792-799.
11. Trask PC, Paterson A, Riba M, et al. Assessment of psychological distress in prospective bone marrow transplant patients. Bone Marrow Transplant. 2002;29(11):917-925.

12. Pillay B, Lee SJ, Katona L, Burney S, Avery S. Psychosocial factors predicting survival after allogeneic stem cell transplant. Support Care Cancer. 2014;22(9):2547-2555.

13. Grulke N, Larbig W, Kächele H, Bailer H. Pre-transplant depression as risk factor for survival of patients undergoing allogeneic haematopoietic stem cell transplantation. Psychooncology. 2008;17(5):480-487.

14. Mumby PB, Hurley C, Samsi M, Thilges S, Parthasarathy M, Stiff PJ. Predictors of non-compliance in autologous hematopoietic SCT patients undergoing out-patient transplants. Bone Marrow Transplant. 2012;47(4):556-561.

15. Syrjala KL, Chapko MK, Vitaliano PP, Cummings C, Sullivan KM. Recovery after allogeneic marrow transplantation: prospective study of predictors of long-term physical and psychosocial functioning. Bone Marrow Transplant. 1993;11(4):319-327.

16. Artherholt SB, Hong F, Berry DL, Fann JR. Risk factors for depression in patients undergoing hematopoietic cell transplantation. Biol Blood Marrow Transplant. 2014;20(7):946-950.

17. Kontoyiannis DP, Marr KA, Park BJ, et al. Prospective surveillance for invasive fungal infections in hematopoietic stem cell transplant recipients, 2001-2006: overview of the Transplant-Associated Infection Surveillance Network (TRANSNET) Database. Clin Infect Dis. 2010;50(8):1091-1100.

18. Stout NL, Binkley JM, Schmitz KH, et al. A prospective surveillance model for rehabilitation for women with breast cancer. Cancer. 2012;118(8 Suppl):2191-2200.

19. Stubblefield MD, Mcneely ML, Alfano CM, Mayer DK. A prospective surveillance model for physical rehabilitation of women with breast cancer: chemotherapy-induced peripheral neuropathy. Cancer. 2012;118(8 Suppl):2250-2260.

20. Mitchell A. Screening procedures for psychosocial distress. In: Holland JC, Breitbart WS, Jacosen PB, et al, editors. Psycho-Oncology. New York: Oxford University Press; 2010:389-396.

21. Jacobsen PB, Donovan KA, Trask PC, et al. Screening for psychologic distress in ambulatory cancer patients. Cancer. 2005;103(7): 1494-1502.

22. Ransom S, Jacobsen PB, Booth-jones M. Validation of the Distress Thermometer with bone marrow transplant patients. Psychooncology. 2006;15(7):604-612.

23. Mahoney FI, Barthel DW. Functional evaluation: the Barthel Index. Md State Med J. 1965;14:61-65.

24. Zochling J, Stucki G, Grill E, Braun J. A comparative study of patientreported functional outcomes in acute rheumatoid arthritis. J Rheumatol. 2007;34(1):64-69.

25. Braido F, Baiardini I, Menoni S, et al. Disability in COPD and its relationship to clinical and patient-reported outcomes. Curr Med Res Opin. 2011;27(5):981-986.

26. Ploughman M, Austin M, Stefanelli M, Godwin M. Applying cognitive debriefing to pre-test patient-reported outcomes in older people with multiple sclerosis. Qual Life Res. 2010;19(4):483-487.

27. Shah S, Vanclay F, Cooper B. Improving the sensitivity of the Barthel Index for stroke rehabilitation. J Clin Epidemiol. 1989;42(8): 703-709. 


\section{Supplementary material}

Table SI Distress Thermometer and abbreviated Barthel Index results

\begin{tabular}{|c|c|c|}
\hline \multicolumn{2}{|l|}{ Barthel questionnaire $(n=80)$} & Number \\
\hline \multicolumn{3}{|l|}{ Self-care (point value, maximum of 45 points) } \\
\hline \multicolumn{2}{|l|}{ I have no problems dressing myself (I0) } & 76 \\
\hline \multicolumn{2}{|l|}{ I have some problems (5) } & 4 \\
\hline \multicolumn{2}{|l|}{ Unable to wash or dress myself $(0)$} & 0 \\
\hline \multicolumn{3}{|l|}{ Ambulating 50 feet (point value) } \\
\hline \multicolumn{2}{|l|}{ I can walk 50 feet by myself (I5) } & 80 \\
\hline \multicolumn{2}{|l|}{ I need someone to support me $(10)$} & 0 \\
\hline \multicolumn{2}{|l|}{ I can use a wheelchair (5) } & 0 \\
\hline \multicolumn{2}{|l|}{ Cannot perform $(0)$} & 0 \\
\hline \multicolumn{3}{|l|}{ Climbing stairs (point value) } \\
\hline \multicolumn{2}{|l|}{ Can walk independently without a handrail (I0) } & 45 \\
\hline \multicolumn{2}{|l|}{ I need a handrail (5) } & 32 \\
\hline \multicolumn{2}{|l|}{ I cannot perform this $(0)$} & 3 \\
\hline \multicolumn{3}{|l|}{ Bathing (point value) } \\
\hline \multicolumn{2}{|l|}{ Independent or in shower (5) } & 77 \\
\hline \multicolumn{2}{|l|}{ Not independent, needs help $(0)$} & 3 \\
\hline \multicolumn{3}{|l|}{ Grooming } \\
\hline \multicolumn{2}{|l|}{ Can brush hair/teeth independently (5) } & 78 \\
\hline \multicolumn{2}{|l|}{ Needs assistance $(0)$} & 2 \\
\hline \multirow{2}{*}{\multicolumn{2}{|c|}{ Distress Thermometer $(n=80)$}} & No \\
\hline \multicolumn{2}{|l|}{ Practical problems } & \\
\hline Child care & 1 & 79 \\
\hline Housing & 5 & 75 \\
\hline Insurance/financial & 17 & 63 \\
\hline Transportation & 5 & 75 \\
\hline Work/school & 7 & 73 \\
\hline \multicolumn{3}{|l|}{ Family problems } \\
\hline Dealing with children & I & 79 \\
\hline Dealing with spouse/partner & I & 79 \\
\hline Dealing with friend/relative & 2 & 78 \\
\hline
\end{tabular}

Patient Related Outcome Measures

\section{Publish your work in this journal}

Patient Related Outcome Measures is an international, peer-reviewed, open access journal focusing on treatment outcomes specifically relevant to patients. All aspects of patient care are addressed within the journal and practitioners from all disciplines are invited to submit their work as well as healthcare researchers and patient support groups.

\begin{tabular}{|c|c|c|}
\hline Distress Thermometer $(n=80)$ & Yes & No \\
\hline \multicolumn{3}{|l|}{ Emotional problems } \\
\hline Depression & 6 & 74 \\
\hline Fears & 15 & 65 \\
\hline Nervousness & 23 & 57 \\
\hline Sadness & 10 & 70 \\
\hline Worry & 21 & 59 \\
\hline Loss of interest & 4 & 76 \\
\hline Spiritual/religious concerns & I & 79 \\
\hline \multicolumn{3}{|l|}{ Physical problems } \\
\hline Appearance & 7 & 73 \\
\hline Bathing/dressing & 2 & 78 \\
\hline Breathing & 2 & 78 \\
\hline Urination changes & 6 & 74 \\
\hline Constipation & 16 & 64 \\
\hline Diarrhea & 7 & 73 \\
\hline Eating & 10 & 70 \\
\hline Fatigue & 24 & 56 \\
\hline Feeling swollen & 6 & 74 \\
\hline Fevers & I & 79 \\
\hline Getting around & 5 & 75 \\
\hline Indigestion & 4 & 76 \\
\hline Memory/concentration & 12 & 68 \\
\hline Mouth sores & 2 & 78 \\
\hline Nausea & 27 & 53 \\
\hline Nose dry/congested & 15 & 65 \\
\hline Pain & 24 & 56 \\
\hline Sexual & 4 & 76 \\
\hline Dry skin & 20 & 60 \\
\hline Sleep & 31 & 49 \\
\hline Tingling in hands/feet & 27 & 53 \\
\hline
\end{tabular}

The journal is included in PubMed. The manuscript management system is completely online and includes a very quick and fair peer-review system. Visit http://www.dovepress.com/testimonials.php to read real quotes from published authors. 